Bull. Fac . Agric., Cairo Univ.,64:340-347 (2013).

\title{
THE ECONOMICS OF APPLE PRODUCTION IN SHOUBAK/JORDAN
}

(Received: 6.12.2013)

\author{
By \\ M. A. Bdour \\ Plant Production Department, Faculty of Agriculture, Mu'tah/University/Jordan
}

\begin{abstract}
This study aimed to identify the economic feasibility of apple cultivation in Shoubak, and to estimate the economic indicators of its cultivation. The initial field data were collected using a questionnaire. The descriptive statistical analysis was used to calculate some statistical indicators and to calculate the total costs, and the total revenues, and net present value discounted measures, used to find investment analysis measures.

The results of the analysis showed that the investment costs for the project amounted to (148) thousand JDs, and the cost of producing one ton of apples (134) JD, and the project's cash flow was negative in the first and the second years raised to (191) thousand JD in the years of top production. The percentage of internal rate of return was $(36,8 \%)$, and the benefit-cost ratio $(2,4)$ the net present value $(954)$ thousand JD, and the rate of return on investment $(15.4 \%)$. The results showed that the internal rate of return recorded up to $(16.9 \%)$ at the high cost $(100 \%)$, and with $15 \%$ decrease in prices, the internal profit decrease to $0.06 \%$, and the investment is profitable. The study recommended investment in cultivating apples and building dams to store rain water to reduce the effects of climate change in amount of groundwater reserves in the Highlands of Shoubak.
\end{abstract}

Key words: apple, costs, net revenues, production, project sensitivity.

$$
\begin{aligned}
& \text { اقتصاديات إنتاج التفاح في لواء الثويك / الأردن } \\
& \text { محمد علي البدور } \\
& \text { قسم الإنتاج النباتي ـ كلية الزراعة ـ جامعة مؤتة ـ الأردن }
\end{aligned}
$$

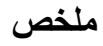

تهذف هذه الدر اسة للتعرف على الجدوى الاقتصادية لزر اعة التفاح في الثوبك / الأردن وتوفير مؤشرات اقتصادية للاستثمار في

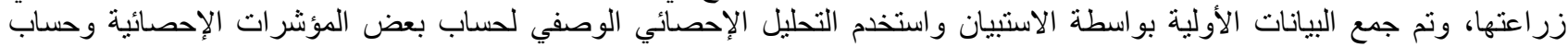

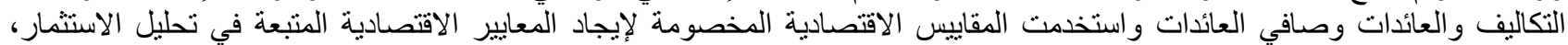

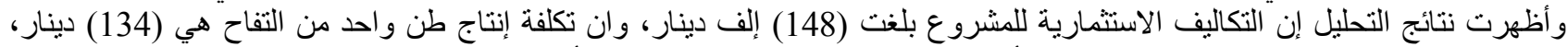

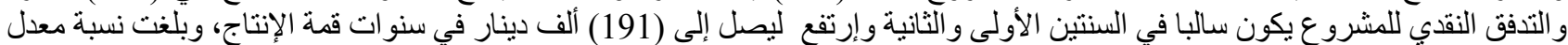

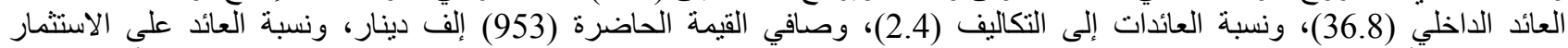

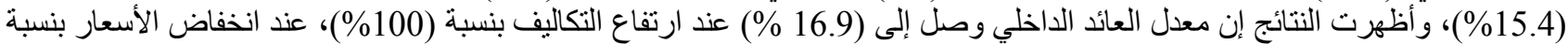

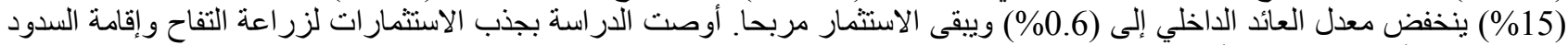

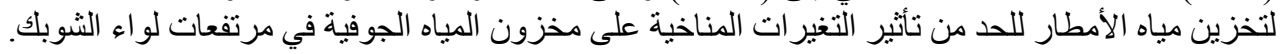

وتعتبر منطقة لواء الثوبك من المناطق الرئيسية في زراعة التفاح

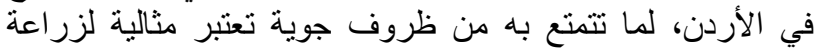

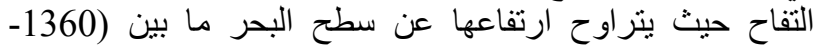

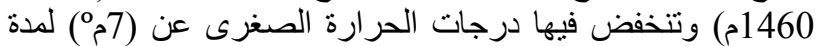

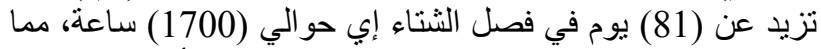
يسهم بشكل كافي في كسر طور السكون لبراعم الأشجار وتكوين

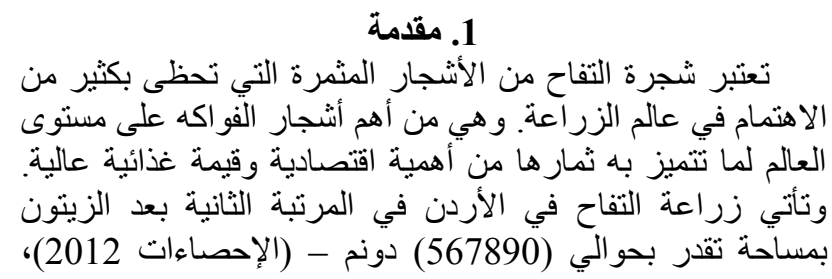

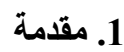

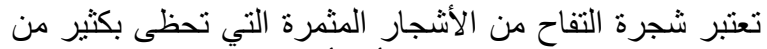

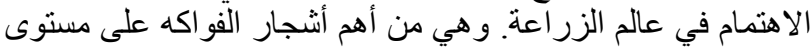

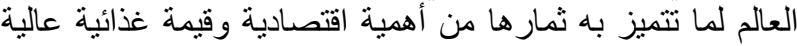
بمساحة تقدر بحو الي (567890) دونم - (الإحصاءات في الأرد فئنة 2012)، 


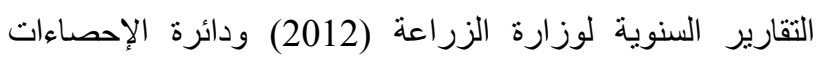

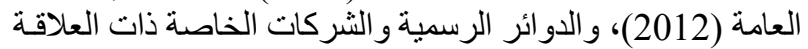
الداسات السابقة قام حنا (2010م )، بدر اسة الكفاءة الاقتصادية لإنتاج التفاح في الإني

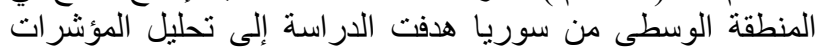

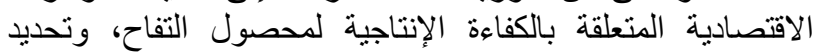

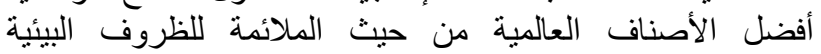

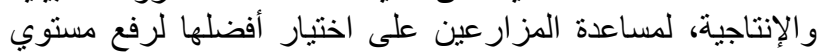

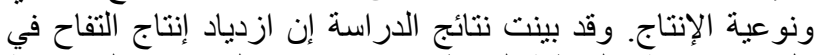

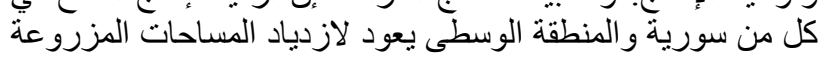

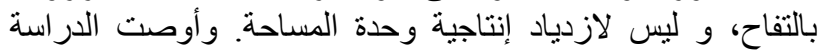

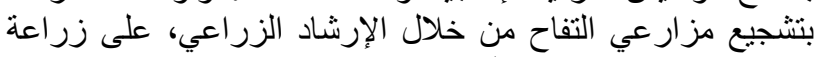

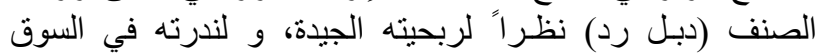

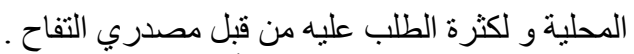

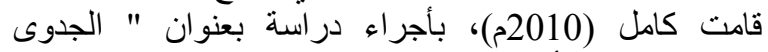

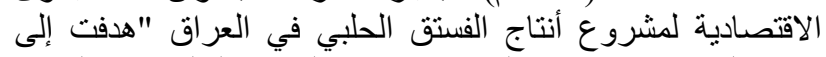

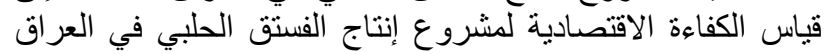

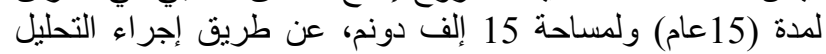

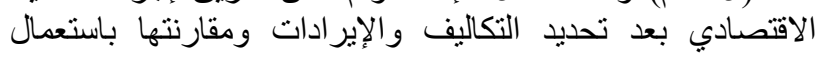

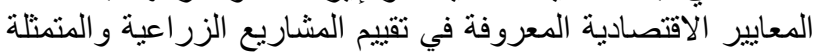

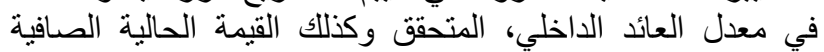

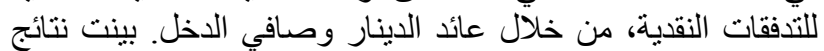

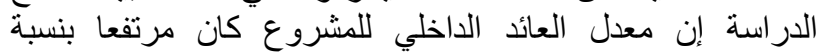

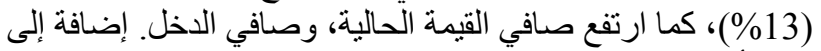

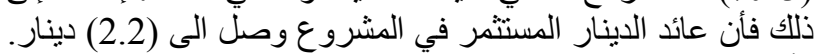

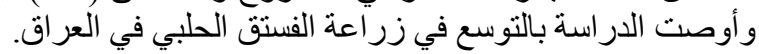

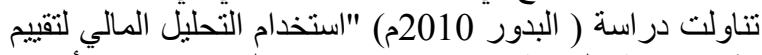

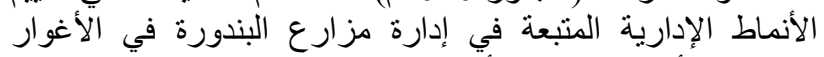

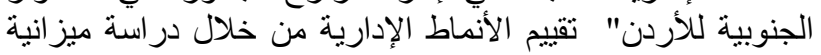

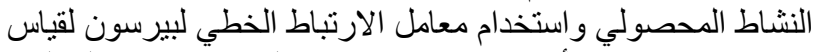

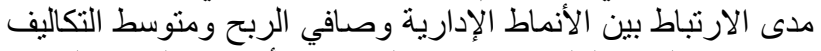

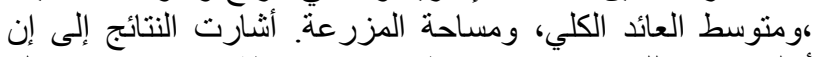

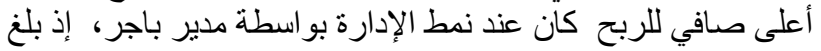

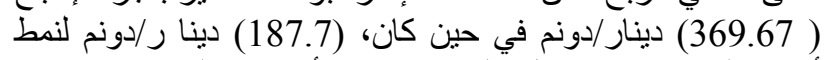

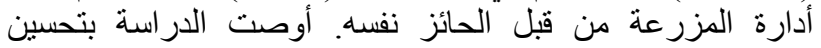

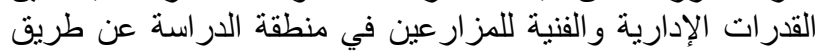

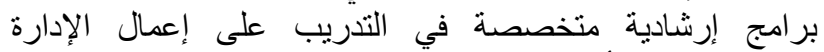

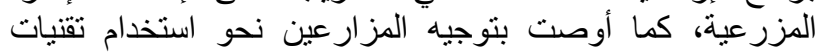

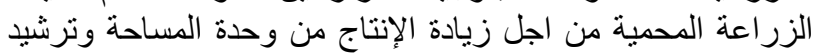
استخدام مياه الري. أجرى يوسف ( 2006م)، بحثناً بعنوان "دراسة تحليلية لتكاليف

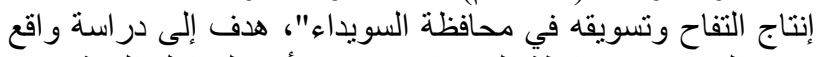

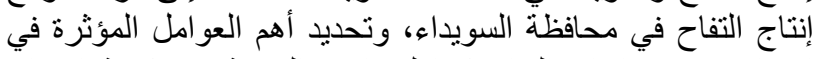
الإنتاج وتقدير إنتاج التفاح كعامل تابع والعلاقة ولثة بين كمية الإنتاج

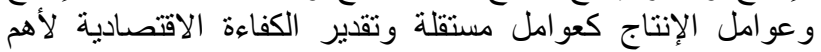

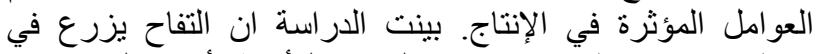

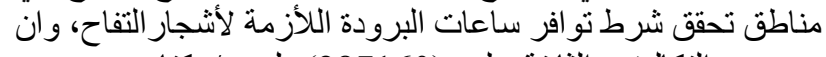

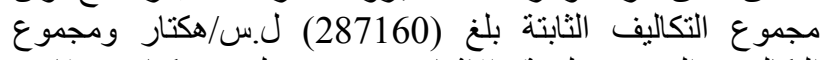

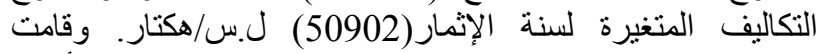

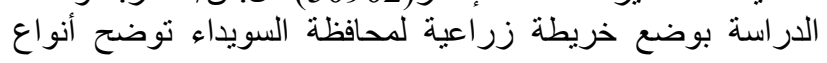

الإز هار من البر اعم الثمرية، وصيفها معتدل جاف يحسن من جودة

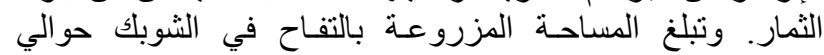

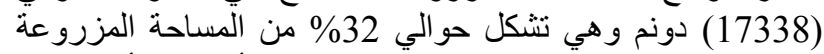

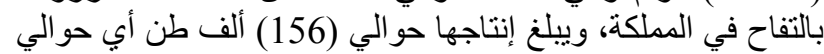

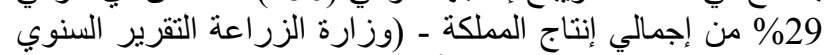

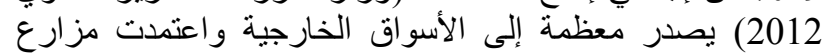

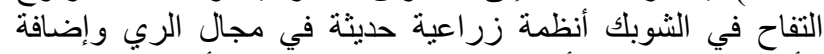

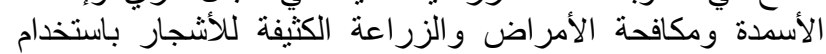

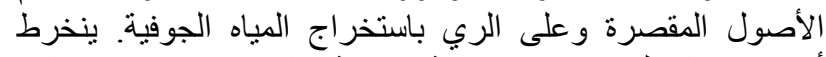

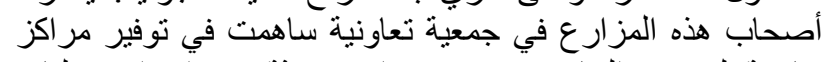

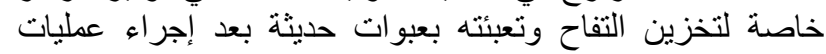

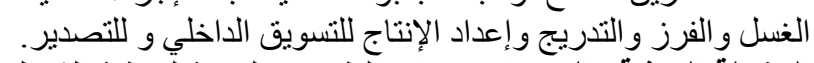

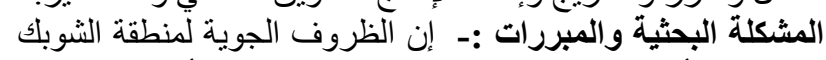

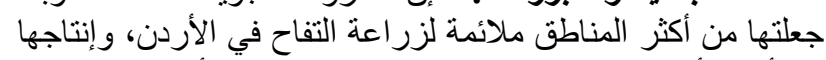

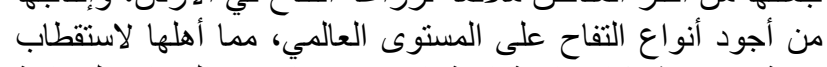

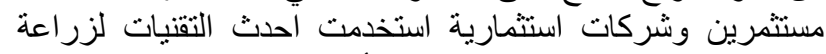

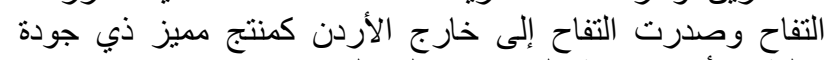

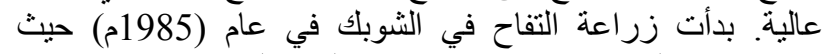

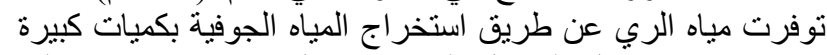

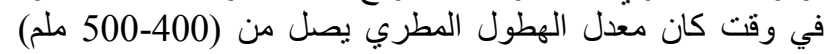

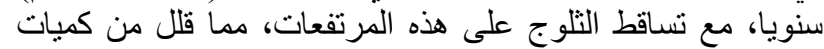

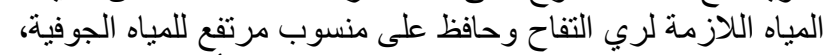

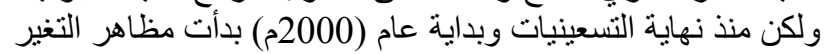

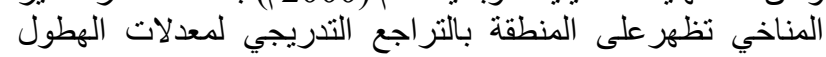

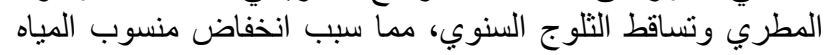

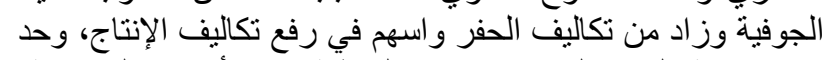

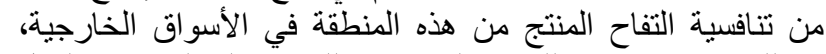

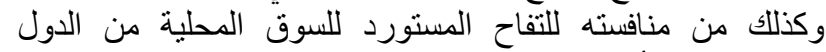

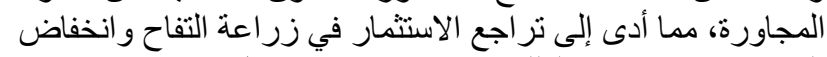

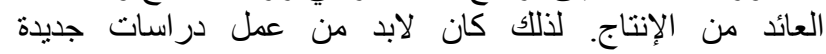

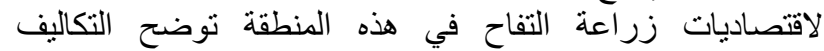

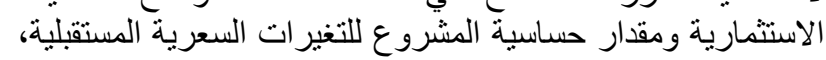

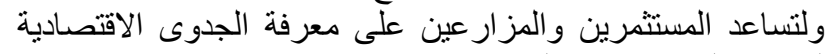
لز أزر اعة التفاح في هذه المنطقة.

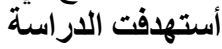

1- التعرف على الجدوى الاقتصادية لزر اعة التفاح في الثوبك.

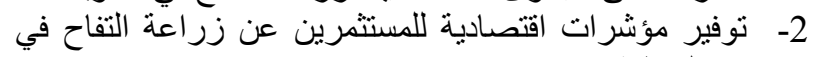

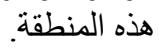

2. الأسلوب البحثي ومصادر البيانات

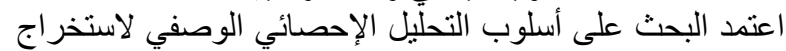
المتوسطات الحسابية لحساب التكاليف التأسيسية (التكاليف التيليف الثابنة) و التكاليف المتغيرة والكلية، واحتساب المعايير الاقتصادية التئية التالية :-

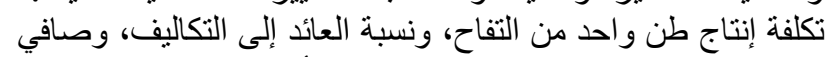

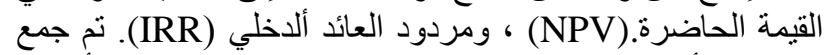
البيانات الأولية بواسطة الاستبيان، الذي تم تصميمه لتحقيق التيق أهداف

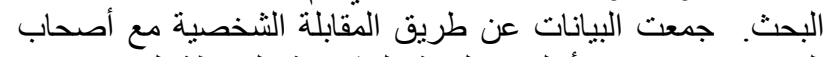

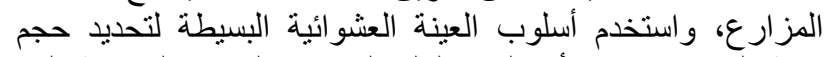

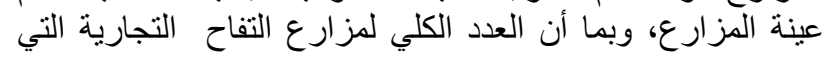

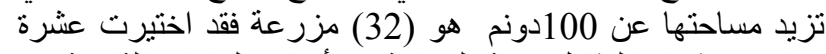
مزارع عشو ائيا لتنكل عينة الدراسة ، وأخذا مزت البيانات الثانوية من 


\begin{tabular}{|c|c|}
\hline التكاليف (دينار / دونم) & السنة \\
\hline 2.76 & 1 \\
\hline 3.83 & 2 \\
\hline 6.05 & 3 \\
\hline 7.17 & 4 \\
\hline 8.27 & 5 ومما بعد ها \\
\hline
\end{tabular}

2- تكاليف مياه الري : يروى التفاح في منطقة الشوبك حو الي (36-

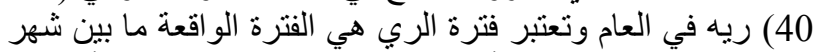

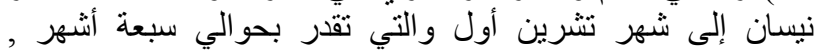
و الجدول رقم (3) يبين تكاليف الري اللدونم، خلال الخدم الخمس سنوات

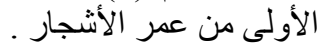

جدول رقم (3): تكاليف الري للاونم من التفاح في منطقة.

\begin{tabular}{|c|c|c|}
\hline التكاليف (دينار/دونم) & كمية المياه/م3 دونم & السنة \\
\hline 4.19 & 257.1 & 1 \\
\hline 6.53 & 349 & 2 \\
\hline 8.2 & 456 & 3 \\
\hline 8.6 & 526 & 4 \\
\hline 9.2 & 570 & 5 \\
\hline
\end{tabular}

3- تكاليف الاسمده: يبين الجدول (4) أنواع الاسمده و كمباتها

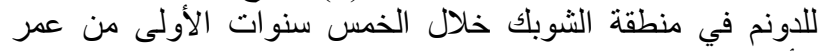
الأشجار حيث تقدر تكاليف الاسمده للاونم بنحو (32) دينار في الأن السنة

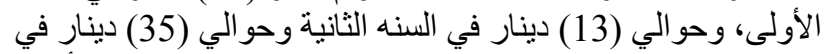

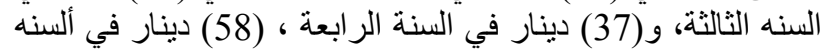
الخامسة وما بعدها.

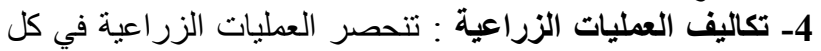

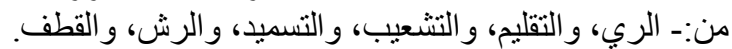
اـ تكاليف عمليات الري:- يحتاج التفاح إلى ري بشئ والثكل شبه مستمر وقدر عدد الريات للموسم بحوالي (40) ريهاج وبات الريمدد زمنية مختلفة.

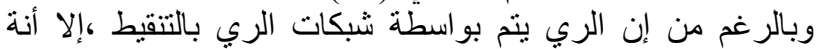

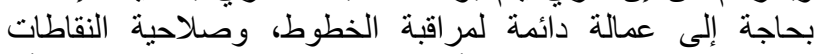

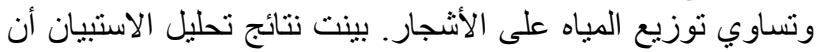

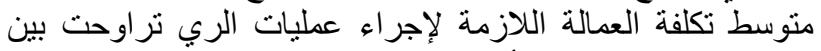

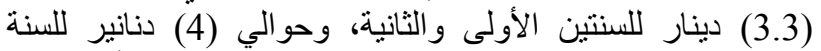

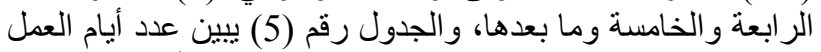

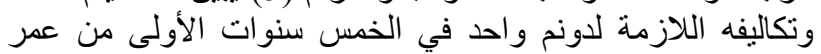

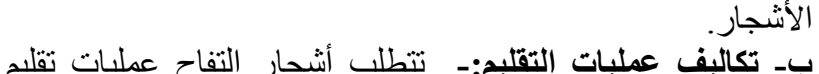

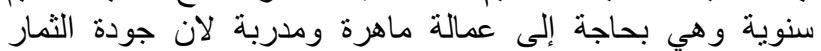

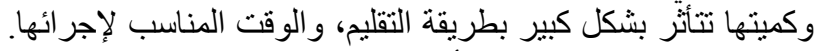

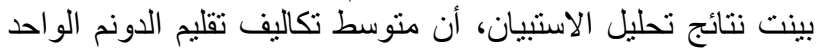

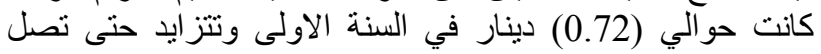

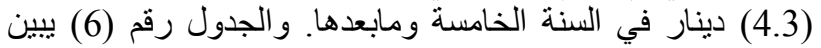
تكاليف عمليات التقليم للدونم الواحد.
الزراعات حسب المناخ، ومعدل الإمطار ودرجات الحرارة و إنشاء

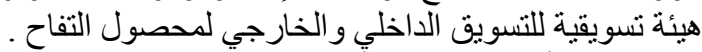

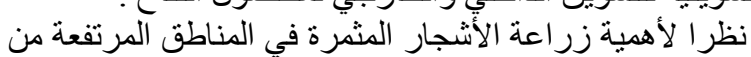

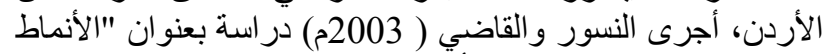

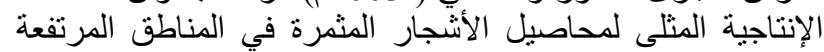

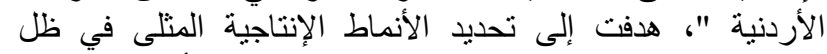

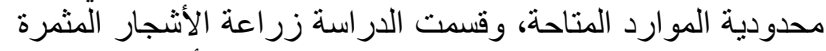

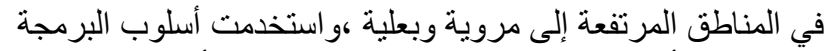

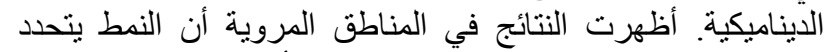

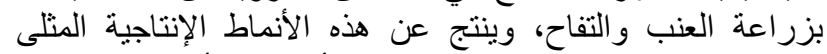

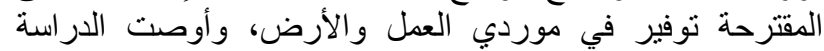

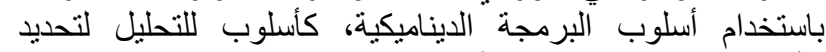

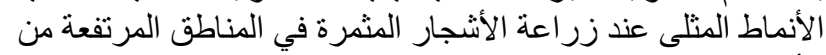

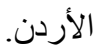

فرضيات الدراسة :- اعتمدت الدر اسة على الفرضيات التالية :

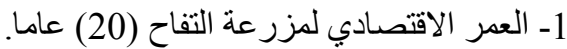

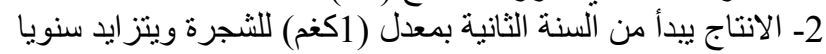

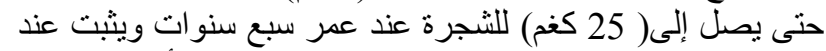

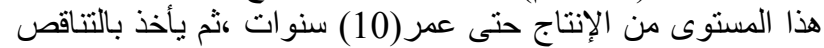
بعد ذللك حتى يصل (10) كغم عند عمر (20) عالأما.

\section{3. النتائج والمناقشة}

التكاليف:- استخلصت التكاليف من نتائج تحليل الاستبيان وقسمت

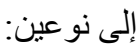
أ- تكاليف ثابتة (تكاليف تأسيسية):- واحتسب متوسط نكاليف

الدونم الواحد من عينة المزارع كما هو موضح في الجدول (1).

\begin{tabular}{|c|c|c|}
\hline & (1): التكاليف التأسيسية دينار/ للاونم. & 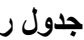 \\
\hline /للاونماليف (دينار & العملية & الرقم \\
\hline 200 & ثمن الأرض & 1 \\
\hline 15.45 & الحراثة العميقة بواسطة ( البلدوزر) & 2 \\
\hline 8.5 & تسوية الأرض وإزالة الحجارة & 3 \\
\hline 0.95 & الحراثة السطحية & 4 \\
\hline 3.42 & تعدير الثوارع الداخلية وتسويتها & 5 \\
\hline 12.8 & تخطيط الأرض وحفر الجور & 6 \\
\hline 3 & زراعة الغراس & 7 \\
\hline 0.34 & زراعة مصدات الرياح & 8 \\
\hline 10.6 & الأسلاك الثائكة & 9 \\
\hline 125 & شبكات الري & 10 \\
\hline 1.25 & ثُمن غراس(ثُمن الثتلة الواحدة) & 11 \\
\hline 15800 & تكاليف البئر (حفر+ تظليف) & 12 \\
\hline 13650 & محركات + مضخات & 13 \\
\hline
\end{tabular}

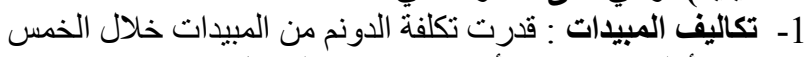

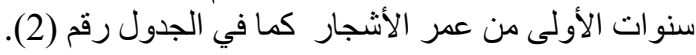


جدول رقم (4): أنواع الأسمة وكمياتها وتكلفاتها للاونم في منطقةالشويك خلال الخمس سنوات الأولي من عمر الأشجار.

\begin{tabular}{|c|c|c|c|c|c|c|c|c|c|c|}
\hline \multicolumn{2}{|c|}{ السنة الخامسة } & \multicolumn{2}{|c|}{ السنة /الر ابعة } & \multicolumn{2}{|c|}{ السنة /الثالثة } & \multicolumn{2}{|c|}{ السنة /الثانية } & \multicolumn{2}{|c|}{ السنة /الأولى } & \multirow[t]{2}{*}{ أنواع السماد } \\
\hline دينار & الكمية & دينار & الكمية & دينار & الكمية & دينار & الكمية & دينار & الكمية & \\
\hline 7.98 & 0.798 & 7.98 & 0.798 & 8.2 & 0.82 & 7.98 & 0.8 & 10.6 & 1.6 & سماد بلاي/طن \\
\hline 7.3 & 0.06 & 3.97 & 0.3 & 4.3 & 0.33 & 2.24 & 0.17 & 1.86 & 14.299 & سماد مركب/كغم \\
\hline & 0.06 & 2.8 & 0.28 & 2.5 & 0.025 & 1.6 & 0.16 & 1.78 & 1.34 & سلفات امونياك/كغم \\
\hline 2.35 & 0.024 & 1.54 & 0.16 & 1.1 & 0.011 & 3.7 & 0.73 & 2.6 & 0.26 & سماد يوريا/كغم \\
\hline 4.63 & 0.055 & 4.63 & 0.77 & 5.38 & 0.089 & 0.48 & 0.097 & - & - & أسمدة ذائبة/كفم \\
\hline 3.31 & 0.055 & 3.31 & 0.55 & - & - & - & - & - & - & عناصر نادرة/كغم \\
\hline 26.52 & 0.044 & 13.16 & 0.022 & 13.16 & 0.22 & - & - & - & - & شيلات حديد/كفم \\
\hline 58.09 & & 37.3 & & 34.7 & & 13.03 & & 32.05 & & \\
\hline
\end{tabular}




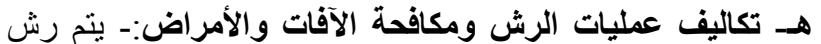

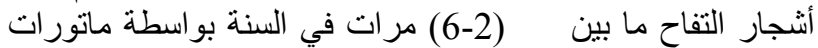

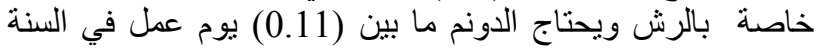

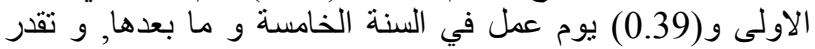

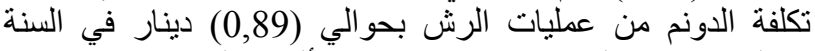
الاولى وترتفع إلى (4.65) دينارا في ألسنه الخامسة وماً بعدها و الجدول رقم (9) يبين ذلك .

جدول (9) : تكاليف عمليات الرش ومكافحة الآفات

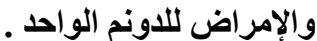

\begin{tabular}{|c|c|c|}
\hline التكلفة (دينار/ دونم) & & \\
\hline 0.89 & 0.11 & 1 \\
\hline 0.33 & 0.33 & 2 \\
\hline 3.09 & 0.39 & 3 \\
\hline 4.65 & 0.39 & 4 \\
\hline 4.65 & 0.39 & 5 \\
\hline
\end{tabular}

و- تكاليف عمليات جمع المحصول:- تبدأ عمليات جمع المحصول

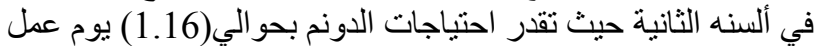

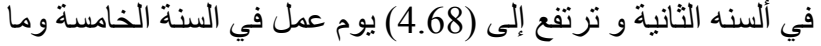

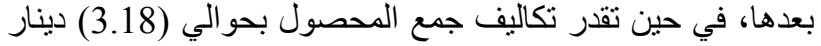

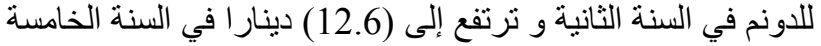
وما بعدها ، و الجدول رقم (10) ييين ذلك.

الجدول رقم (10): تكاليف عمليات جمع المحصول للاونم الواحد.

\begin{tabular}{|c|c|c|}
\hline التكلفة (دينار/ دونم) & احتياجات الدونم (يوم عمل) & السنة \\
\hline- & - & 1 \\
\hline 3.18 & 1.16 & 2 \\
\hline 5.34 & 2.00 & 3 \\
\hline 10.00 & 3.78 & 4 \\
\hline 12.60 & 4.68 & 5 \\
\hline
\end{tabular}

تكاليف الإنتاج

أظهرت نتائج تحليل الاستبيان، إن جميع مزارع عينة الدراسة

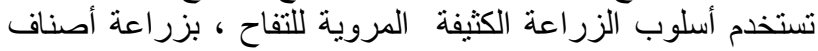

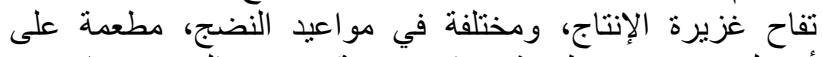

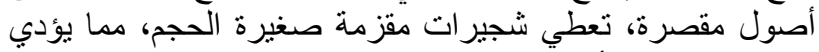

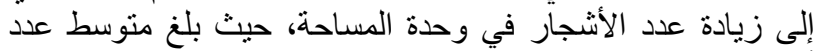

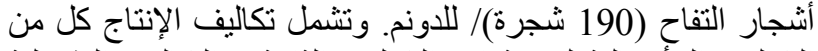
التكاليف الرأسمالية للاستثمار (التكاليف الثابتة) و التكاليف التئنة التشغيلية

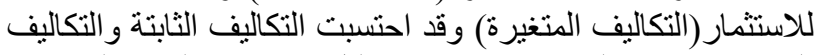

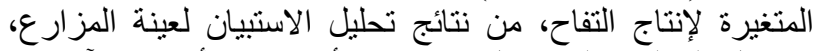

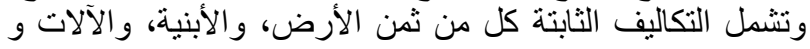

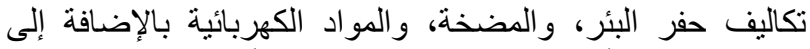
تكاليف إعداد الأرض و الحراثة والزئة والزراعة ، أما التكاليف المنغيرة

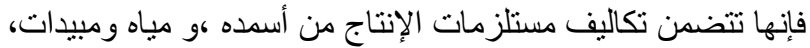

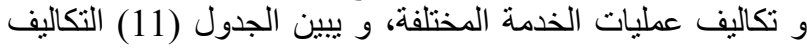

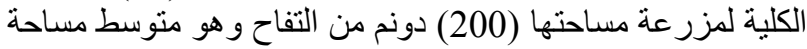
مزارع العينة البحثية في لواء الثنوبك , وقد بلغت التكاليف الكلية
الجدول رقم (5): عدد ايام العمل اللازمة للري للاونم الواحد.

\begin{tabular}{|c|c|c|}
\hline التكاليف (دينار/دونم) & يوم عمل/ للاونم & السنه \\
\hline 1.13 & 1.19 & 1 \\
\hline 2.59 & 0.99 & 2 \\
\hline 4.9 & 1.87 & 3 \\
\hline 4 & 1.57 & 4 \\
\hline 4 & 1.57 & 5 \\
\hline
\end{tabular}

جدول رقم (6): عدد أيام العمل اللازمة للتقليم وتكاليفها.

\begin{tabular}{|c|c|c|}
\hline التكاليف (دينار/دونم) & يوم عمل/ للاونم & السنه \\
\hline 0.72 & 0.26 & 1 \\
\hline 1.24 & .0 .43 & 2 \\
\hline 1.24 & 0.56 & 3 \\
\hline 2.90 & 0.95 & 4 \\
\hline 4.3 & 1.48 & 5 \\
\hline
\end{tabular}

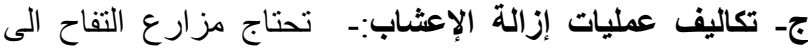

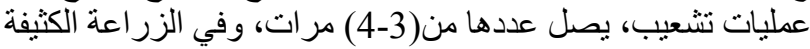

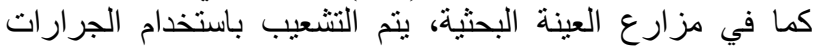
الزر اعية صغيرة الحجم و المحاريث السطحية ولكن لإبـ لابد من استخدام

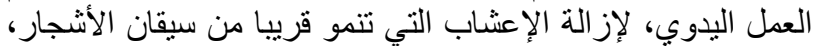

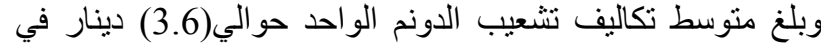
السنة الاولى تتزايد حتي تبلغ (7.6) دينار في السنة الندالئ الخامسة

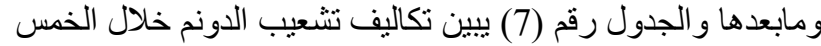

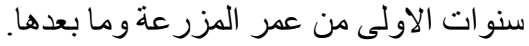

جدول رقم (7): تكاليف عمليات التشعيب للخمس سنوات الاولى من عمر المزرعة وما بات بعدها.

\begin{tabular}{|c|c|c|}
\hline التكلقة (دينار / دونم) & يوم عمل /للاونم & السنة \\
\hline 3.64 & 1.42 & 1 \\
\hline 5.90 & 2.14 & 2 \\
\hline 7.40 & 2.37 & 3 \\
\hline 7.57 & 2.8 & 4 \\
\hline 7.60 & 2.8 & 5 وما بعدها \\
\hline
\end{tabular}

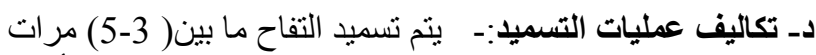

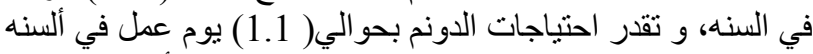

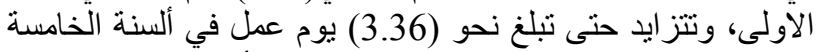

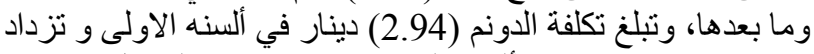

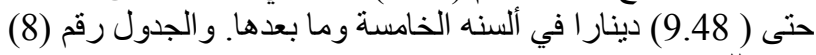

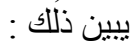

جدول رقم (8) :تكاليف عمليات التسميد للخمس سنوات الاولى من عمر المزرعة وما بعدها.

\begin{tabular}{|c|c|c|}
\hline التكلفة (دينار/ دونم) & يوم عمل /للاونم & السنة \\
\hline 2.94 & 1.1 & 1 \\
\hline 7.10 & 2.57 & 2 \\
\hline 8.55 & 3.00 & 3 \\
\hline 8.55 & 3.00 & 4 \\
\hline 9.48 & 3.36 & 5 \\
\hline
\end{tabular}




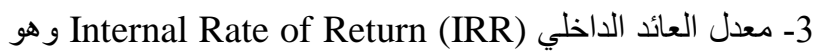

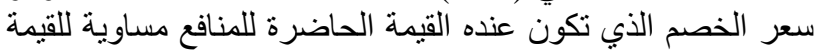

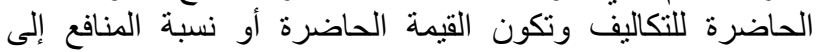

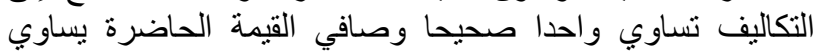

حوالي (183) ألف دينار في السنة الاولى, و نحو (19) الفئل إلف دينار في السنة الثنانية و حو الي (26) ألف دينار في السنة النئة الثالثة, و و(29) إلف دينار في السنة الرابعة وحوالي (36) ألف دينار في السنة

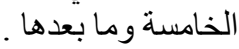
صفرا. جدول (11): التكاليف الكلية للخمس سنوات الاولى من عمر المزرعة.

\begin{tabular}{|c|c|c|c|c|c|}
\hline الخامسة & الرابعة & الثالثة & الثانية & الاولى & التكاليف/دينار السنوات \\
\hline- & - & - & - & 40000 & ثمن الأرض \\
\hline- & - & - & - & 1000 & مستودعات ومباني \\
\hline- & - & - & - & 12000 & آلات ومعدات \\
\hline- & - & - & - & 15800 & حفر بئر \\
\hline- & - & - & - & 13650 & مضخات \\
\hline- & - & - & - & 684 & طرق \\
\hline- & - & - & - & 2120 & اسل \\
\hline- & - & - & - & 68 & مصدات رياح \\
\hline- & - & - & - & 3090 & حراثه بالبلاوزر \\
\hline- & - & - & - & 1700 & تسوية الارض \\
\hline- & - & - & - & 2560 & تخطيط و حفر الجور \\
\hline- & - & - & - & 25000 & ثمن شبكات الري \\
\hline- & - & - & - & 33400 & ثُن الاشتال \\
\hline- & - & - & - & 600 & زراعه \\
\hline 190 & 190 & 190 & 190 & 190 & حراثه سطحيه \\
\hline 3400 & 3400 & 3400 & 3400 & 3400 & عمال دائمون \\
\hline 1820 & 1720 & 1640 & 1306 & 838 & مياه الري \\
\hline 11618 & 7468 & 6940 & 2606 & 6410 & أسمده \\
\hline 1654 & 1434 & 1210 & 764 & 552 & مبيدات \\
\hline 800 & 800 & 800 & 518 & 226 & عمال الري \\
\hline 860 & 580 & 380 & 248 & 144 & عمال التقليم \\
\hline 1520 & 1514 & 1480 & 1180 & 728 & عمال التعثيب \\
\hline 1896 & 1736 & 1516 & 1420 & 588 & عمال التسميا \\
\hline 930 & 930 & 618 & 466 & 178 & عمال الرش \\
\hline 2260 & 2000 & 1068 & 636 & --- & قطف \\
\hline 7000 & 6000 & 5800 & 5700 & --- & صيانه \\
\hline 33948 & 27752 & 25042 & 18196 & 174326 & المجموع \\
\hline 1697 & 1388 & 1252 & 910 & 8716 & تكاليف غير منظوره 5\% \\
\hline 35645 & 29140 & 26294 & 19106 & 183042 & جملة التكاليف \\
\hline
\end{tabular}

لقد اعتمدت نتائج الدراسة على جمع المعلومات عن العائدات

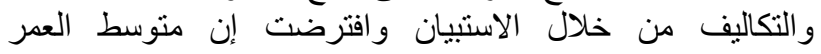

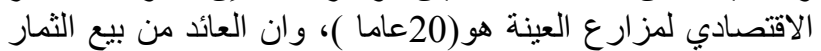

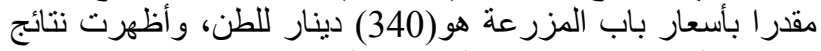

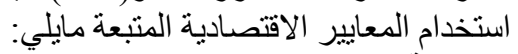
1- تكلفة إنتاج طن واحد من التفاح

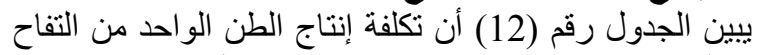

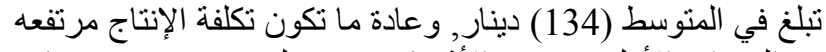
في السنوات الأولى من عمر الأشجار , حيث تبلغ نحو (1581) دينار
المعايير الإقتصاديه: و هي مقاييس تحليل الاستثمار المخصومة التي

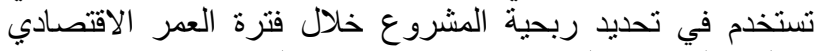

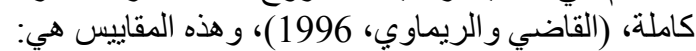

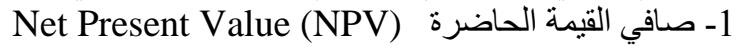
= القيمة الحاضرة للمنافع- القيمة

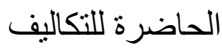

2- نسبة المنافع إلى التكاليف Benefit- Cost Ratio / القيمة الحاضرة للمنافع =

القيمة الحاضرة للتكاليف 
تساوي( 12\%) فأن الاستثمار في زراعة التفاح في لواء الثوبك

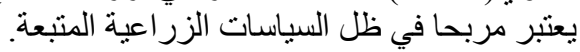
4- صافي القيمة الحاضرة: NPV

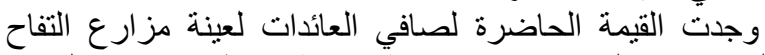

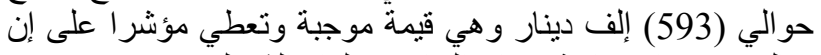

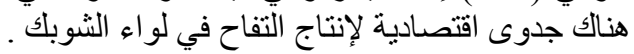

للطن في السنة الثانية، ثم تأخذ التكاليف في الانخفاض، نظر التز ايد

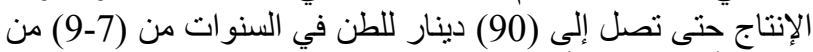

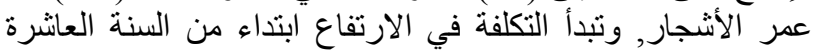
نظرا لتناقص الإنتاجية, ويستمر الارتفاع في التكلفة بتقام عمر الإنة التخرة

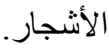

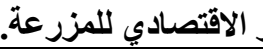

\begin{tabular}{|c|c|c|c|}
\hline تكلفة الطن (دينار) & طن & التياليف / التيار & السنة \\
\hline ---- & ---- & ---- & 1 \\
\hline 1581 & 26.7 & 42217 & 2 \\
\hline 373 & 133.5 & 49837 & 3 \\
\hline 198 & 267.0 & 52853 & 4 \\
\hline 149 & 400.5 & 59749 & 5 \\
\hline 112 & 534.0 & 59749 & 6 \\
\hline 90 & 667.5 & 59749 & 7 \\
\hline 90 & 667.5 & 59749 & 8 \\
\hline 90 & 667.5 & 59749 & 9 \\
\hline 130 & 667.5 & 8693 & 10 \\
\hline 112 & 534.0 & 59645 & 11 \\
\hline 112 & 534.0 & 59645 & 12 \\
\hline 112 & 534.0 & 59645 & 13 \\
\hline 112 & 534.0 & 59645 & 14 \\
\hline 112 & 534.0 & 59645 & 15 \\
\hline 149 & 400.5 & 59645 & 16 \\
\hline 149 & 400.5 & 59645 & 17 \\
\hline 149 & 400.5 & 59645 & 18 \\
\hline 223 & 267.0 & 59645 & 19 \\
\hline 223 & 267.0 & 59645 & 20 \\
\hline 134 & 8437.2 & 1127040 & المجموع \\
\hline
\end{tabular}

5- نسبة العائد إلى التكاليف

لقد احتسبت القيمة الحاضرة للعائدات و القيمة الحاضرة للتكاليف

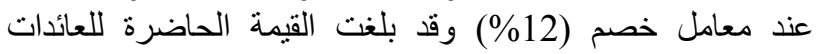
(911) إلف دينار،في حين بلغت القيمة الحاضرة للتكاليف (282)

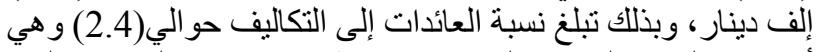
أكبر من الواحد الصحيح لذا يعتبر الاستثمار في إنتاج التفاح في لواء الواء

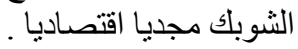

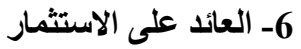

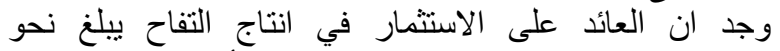
(15.4\%) سنويا، وهو يفوق الفرصة البديلة لرأس المال، ويبرهن

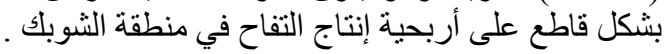

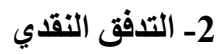
التدفقات النقدية الصافية خلال العمر الاقتصادي للمشروع هي

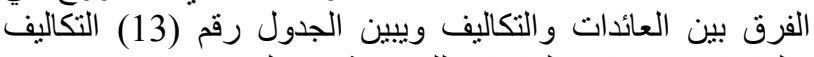

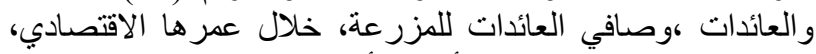

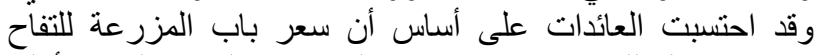

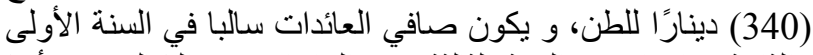

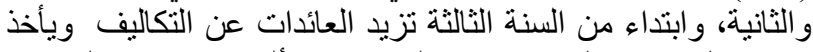
صافي العائدات بالتزايد حنى يبلغ (191) التئن التف دينار في السنوات

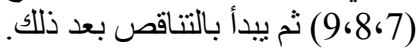

3- معدل العائد الداخلي:

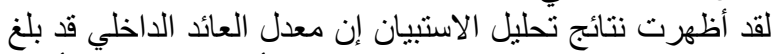

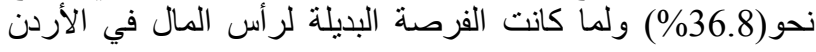


وتتناقص حتى تصل إلى (90) عند قمة الإنتاج ثم تأخذ في التزايد حتى تصل إلى (223) دينار في نهاية العمر الإنتاجي لملأشجار.

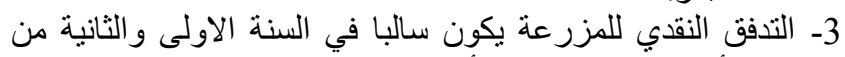

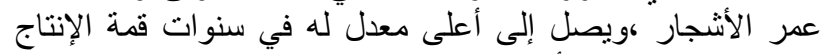
حيث يبلغ نحو (191) ألف بلف دينار.

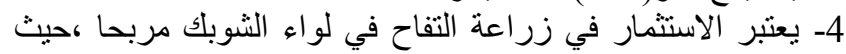

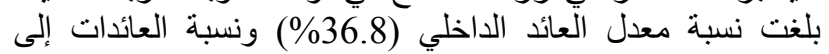

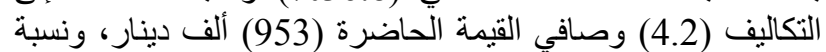
العائد على الاستثمار (4.4 ) 15.4\%) سنويا.

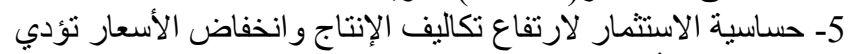

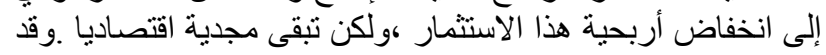

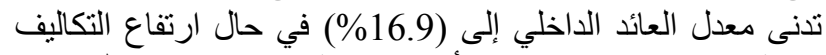
بنسبة (100\%). و انخفاض الأسعار بنسبة (15\%) (15\%) يودي إلى تدني الدي العائد الداخلي بنسبة (0.6\%). (10).

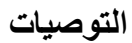

توصي الدراسة بالاستمر ار في الاستثمار في زر اعة التفاح في لو اء لوناء

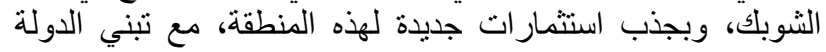

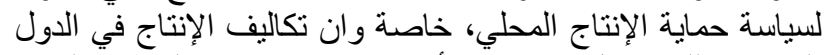

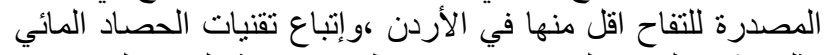

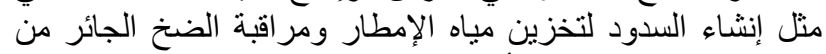
المياه الجوفية وتقنين ري أثنجار التفاح في حدود الاحتباجات الإنيات الميائية

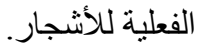

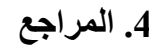

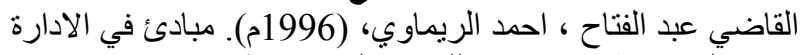

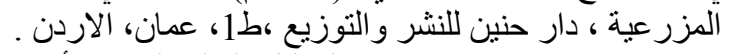

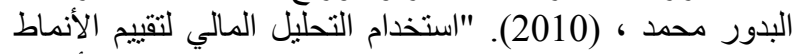

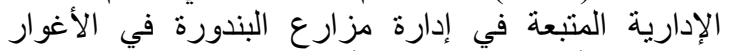

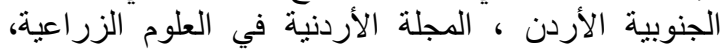
المجلد( 6) ،العدد (2)، الجامعة الاردنية ،عمان ، الاردية الاردن. الإن.

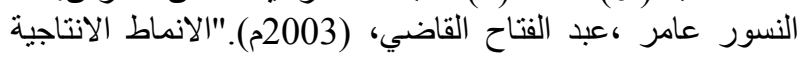

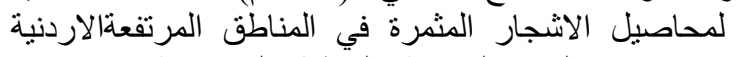

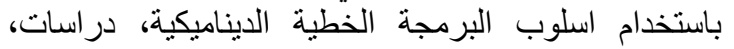

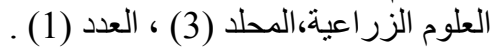
يوسف جزان، (2006م). "دراسة تحليلية لتكاليف انتاج التفاح التهاح

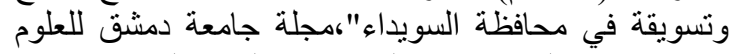
الاقتصادية و القانونية، مجلد (22) العدد الثاني، دمثقة لإنق

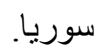
حنا جاك، (2010). "دراسة الكفاءة الاقتصادية لمحصول التفاح

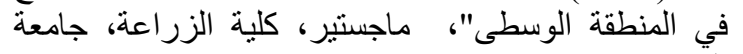

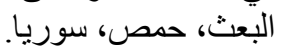

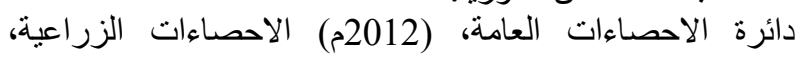

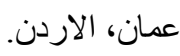

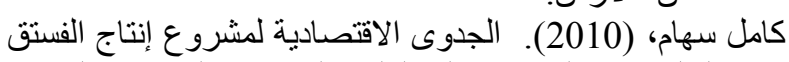

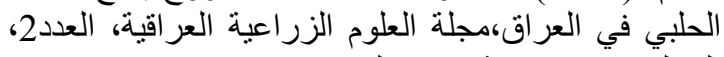

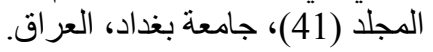
وزرارة الزراعة، (412) جامعة). التقرير السنوي عمان، الاردن.

\begin{tabular}{|c|c|c|c|}
\hline العائداتي & (دينار ) & (دينار) & الستهـ \\
\hline 183042 - & -------- & 183042 & 1 \\
\hline 10028- & 9078 & 19106 & 2 \\
\hline 19096 & 45390 & 26294 & 3 \\
\hline 61640 & 90780 & 29140 & 4 \\
\hline 100525 & 136170 & 35645 & 5 \\
\hline 145915 & 181560 & 35645 & 6 \\
\hline 191305 & 226950 & 35645 & 7 \\
\hline 191305 & 226950 & 35645 & 8 \\
\hline 191305 & 226950 & 35645 & 9 \\
\hline 165655 & 226950 & 61295 & 10 \\
\hline 145915 & 181560 & 35645 & 11 \\
\hline 145915 & 181560 & 35645 & 12 \\
\hline 145915 & 181560 & 35645 & 13 \\
\hline 145915 & 181560 & 35645 & 14 \\
\hline 145915 & 181560 & 35645 & 15 \\
\hline 100525 & 136170 & 35645 & 16 \\
\hline 100525 & 136170 & 35645 & 17 \\
\hline 100525 & 136170 & 35645 & 18 \\
\hline 55135 & 9780 & 35645 & 19 \\
\hline 105135 & 140780 & 35645 & 20 \\
\hline
\end{tabular}

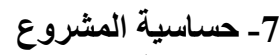
نظر التوقع زيادة قيمة التكاليف خلال فترة العمر الاقتصادي

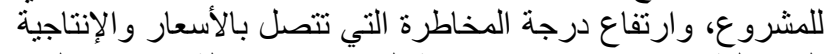

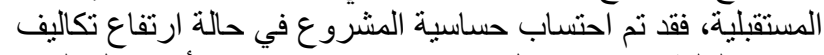

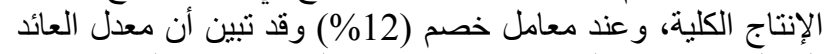
الداخلي ينخفض إلى (28.6\%) في حالة النة (ارتفاع تكاليف الإنتاج بنسبة (25\%) وينخفض إلى (23.8\%) في (20.6\%) في حالة ارتفاع التكاليف

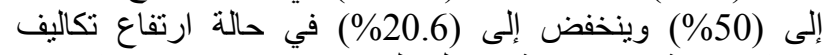

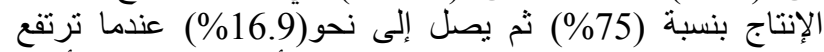

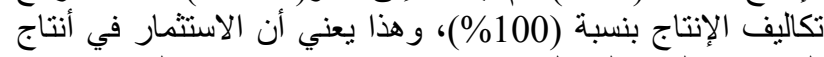

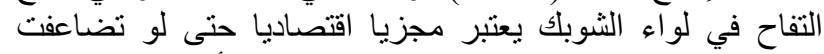

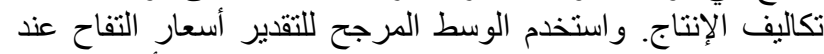

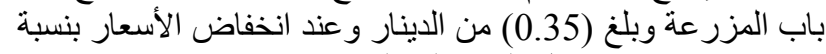

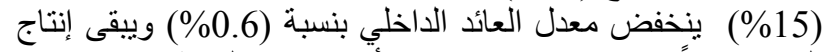
التفاح مجدياً اقتصاديا عند انخفاض الأسعار بهذه النسبة. النتائج 1- التكاليف الثابتة (الاستثمارية ) لمزرعة تفاح مساحتها (200) دونم تبلغ (148) ألف دينار .

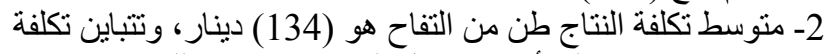

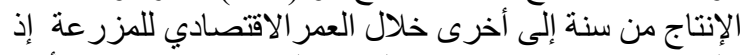

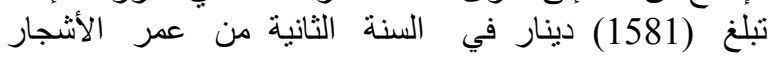

